Acta Theriologica $36(1-2): 131$ - 140, 1991.

PL ISSN $0001-7051$

\title{
Frequency distribution of conception dates in a white-tailed deer herd
}

\author{
Olin E. RHODES, Jr.*, James M. NOVAK, Michael H. SMITH and Paul E. JOHNS
}

Rhodes O. E., Jr., Novak J. M., Smith M. H. and Johns P. E. 1991. Conception dates in a whitetailed deer herd. Acta theriol. 36: 131 - 140.

Conception dates of white-tailed deer, Odocoileus virginianus (Zimmermann, 1780) were estimated for the breeding periods of $1974-76$ and 1984 using fall and winter - spring fetal data. Conception dates estimated from data collected in the fall were biased. This bias resulted in an earlier mean conception date than that based on information which included data from later breeding females. Mean breeding dates differed significantly between female age classes due to delayed conception in fawns which also resulted in a skewed frequency distribution of conception dates. The frequency distribution of conception dates was leptokurtotic, suggesting that the distribution is constrained in time by some factor(s). Conception date estimates did not differ by habitat type but were influenced significantly by period of data collection. Mean breeding date for deer on the Savannah River Site, corrected for age class sampling bias, is 20 November \pm 27 days (adults plus fawns) and 13 November \pm 15 days (only adults).

Department of Aquaculture, Fisheries and Wildlife, Clemson University, Clemson, SC 29631, USA (OER); Savannah River Ecology Laboratory, Drawer E, Aiken, SC 29802, USA (JMN, MHS, and PEJ); Departments of Zoology and Genetics, School of Forest Resources and Institute of Ecology, University of Georgia, Athens, GA 30602, USA (MHS)

Key words: conception dates, Odocoileus virginianus

\section{Introduction}

Reproductive success in most organisms is closely tied to the timing of reproduction (Fisher 1958). For white-tailed deer, Odocoileus virginianus (Zimmermann, 1780), variables including resource availability (McGuinnes and Downing 1977), body condition (Verme 1965), age (Cheatum and Morton 1946), and other demographic variables can alter the onset of breeding activity and the distribution of conception dates (Jacobson et al. 1980). Habitat quality is thought to be one of the most important factors affecting the timing of reproduction. Social relationships within a deer herd may be equally important in determining the distribution of conception dates.

Timing of reproduction in southeastern deer herds may vary greatly between geographic regions (Richter and Labisky 1985). Limitations associated with data collection methods could be partially responsible for these differences. Better estimates of conception dates (CD) could be used to more rigorously test for habitat and density effects on the timing of reproduction in deer herds.

A large, temporally extensive, reproductive data set is available for a deer herd on the Savannah River Plant near Aiken, South Carolina, USA. This herd occurs in both swamp and

*Present address: Department of Range and Wildlife Management, Texas Tech. University, Lubbock, TX 79409 , USA 
upland habitat types. Our primary purpose is to describe the distribution of conception dates (CD) on the Savannah River Plant and to test for effects of female age, habitat, and collection period on estimates of $\mathrm{CD}$. We will also discuss possible constraints on the distribution of $\mathrm{CD}$ for this deer herd and compare the mean $C D$ with those from other herds in the eastern United States.

\section{Methods}

Data were collected from pregnant female deer at check stations during either-sex and any age fall hunts held on the Savannah River Plant in $1974-76(n=160)$ and $1984(n=180)$. Still and dog hunting techniques were used prior to 1980; dog hunting alone was used after that time. Additional collections were made in the late winter and spring during $1975-77$ and 1985. Data from the breeding seasons $1974-76$ were pooled because of low sample sizes within years. Age determined by tooth eruption and wear (Severinghaus 1949), body weight, location, and date of kill were recorded for each animal. Animals were assigned to either upland (planted pine, mixed hardwood) or swamp (planted pine, bottomland hardwood bordering a deep water cypress-black gum swamp) habitat type according to location.

Fetuses were removed from visibly pregnant females during $1974-77(n=285$ fetuses $)$ and $1984-85$ $(n=313)$. Weights in milligrams were taken for all fetuses, with the placenta removed, and weights were averaged for the combined offspring of each pregnant female. For each dec, fetal age in days was estimated using the mean fetal weight in predictive equations for fetal age determined for 39 pen raised white-tailed deer in South Carolina (Hamilton et al. 1985). Because male access to females was controlled, the breeding date of each female was known and the correlation of weight with known age was high $\left(r^{2}=0.98\right)$. Use of fetal weight as a predictor of fetal age has been discouraged for animals with multiple pregnancies (Morrison et al. 1959) partly because fetal weight can be affected by poor quality environmental conditions (Verme and Ullrey 1984). Degree of development and/or body measurements are most often used to age fetal cervids (Armstrong 1950, Cheatum and Morton 1946, Hudson and Browman 1959, Short 1970). Fetal aging techniques based on developmental characters are generally applicable from about 45 days of age onward. This limitation would prevent the estimation of age for approximately one third of our collected fetal samples if developmental criteria alone were used. The predictive equations used by us were based on fetal weight and allowed the estimation of age for all of the fetuses and gave ages for fetuses greater then $\mathbf{4 5}$ days old that were in agreement with those calculated using two standard aging techniques based on fetal development. Prediction of fetal age from fetal weight has also been performed frequently for fallow deer (Dama dama) in England (Armstrong et al. 1969, Chapman and Chapman 1975). Conception date for each pregnant female was calculated by subtracting the fetal age in days from the date of collection expressed in Julian days with 365 days added for females collected after December 31st. Frequency distributions were calculated for each set of CDs estimated for the periods $1974-77$ and $1984-85$. CDs for the breeding periods $1974-76$ and 1984 were also calculated using fall and winter - spring collected fetal data as independent estimates.

Analyses of variance, $t$-tests, and $t^{\prime}$-tests (for samples with non-homogenous variances) were used where appropriate to test for significant differences in CDs between time periods, seasonal collection periods, and female age classes. Data analyses were performed using the Statistical Analysis System (SAS; Barr et al. 1985), and statistical significance was set $a$ priori at the 0.05 probability level and highly significant was designated at 0.01 or less. Confidence intervals are given as plus or minus one standard error except as noted.

\section{Results}

Estimates of CD calculated from fetal data collected in the falls of 1974 - 76 and 1984 were significantly different from those estimates for the same breeding periods using only 
winter - spring collected fetal data (Table 1). Mean CD estimates were plotted against female age class. Fawn females had significantly later mean CDs $(p<0.01)$ than did adults with a trend toward later $\mathrm{CD}$ estimates with decreasing age (Fig. 1). The analysis of variance used to test for differences in fall vs late winter - spring collection period estimates in each breeding season was performed both with and without the data for fawn females and included female age as an additional class variable. When data from fawns were included in the analysis, mean $\mathrm{CD}$ estimates were significantly different between collection periods, and age significantly affected CD estimates in both breeding periods. Approximately $45 \%$ of the variation in the estimated CDs between the collection periods was accounted for by the variables of age and collection period. When data for fawns were dropped from the analysis, the effect of age was no longer significant but period of collection remained highly significant in both breeding periods $(1974-76, F=32$, d.f. $=2,149 ; 1984, F=10$, d.f. $=2,158)$.

Table 1. Four moments for the distribution of conception dates calculated from white-tailed deer fetal weights during different collection periods. Positive kurtosis indicates a leptokurtic distribution while positive and negative skewness indicate later or earlier conception dates than expected in a normal distribution, respectively.

\begin{tabular}{llcrc}
\hline Period & Mean & Variance & Skewness & Kurtosis \\
\hline Spring 1974-76 & $323^{2}$ & $1026^{3}$ & $2.008^{1}$ & $6.370^{1}$ \\
Fall 1974-76 & $294^{1,2}$ & $338^{3,4}$ & $-1.381^{1}$ & $2.256^{1}$ \\
Spring 1984 & $330^{2}$ & $1246^{3}$ & $2.186^{1}$ & $6.129^{1}$ \\
Fall 1984 & $307^{1,2}$ & $204^{3,4}$ & -0.384 & $1.767^{1}$ \\
\hline
\end{tabular}

${ }^{1} p<0.05 ; t$-tests for means, $t$-tests for skewness and kurtosis.

${ }^{3} p<0.01 ; t$ 'tests for means.

${ }^{3,4} p<0.0001 ; F_{\max }$ test for non-homogeneity of variances.

The absolute difference between the mean CD estimated from the fall and late winter spring collection periods was calculated for each breeding period. Data from fawn females were excluded from the analysis due to their significantly later conception dates. The difference between the mean CDs for the 2 periods in the $1974-76$ breeding period ( 23 days) was twice that for the 1984 breeding season estimates (11 days). The CD estimates based on spring collected fetal data were not significantly different between the 2 breeding periods $(t=1.0$, d.f. $=100)$ but those estimates based on fall collected data exhibited a highly significant difference $\left(t^{\prime}=6.0\right.$, d.f. $\left.=238\right)$. Mean CDs were not different for deer from the swamp or upland in either year of collection.

An analysis of variance was used to test for significant differences between CDs estimated from fall collected fetal data for the breeding periods $1974-76$ and 1984. Analyses were performed without the data for fawn females included and with female age as a class variable in addition to year. The difference in CDs was highly significant between the two time periods $(F=9.45)$. Mean $C D$ in the $1974-76$ breeding period was earlier than in 1984 , and females 


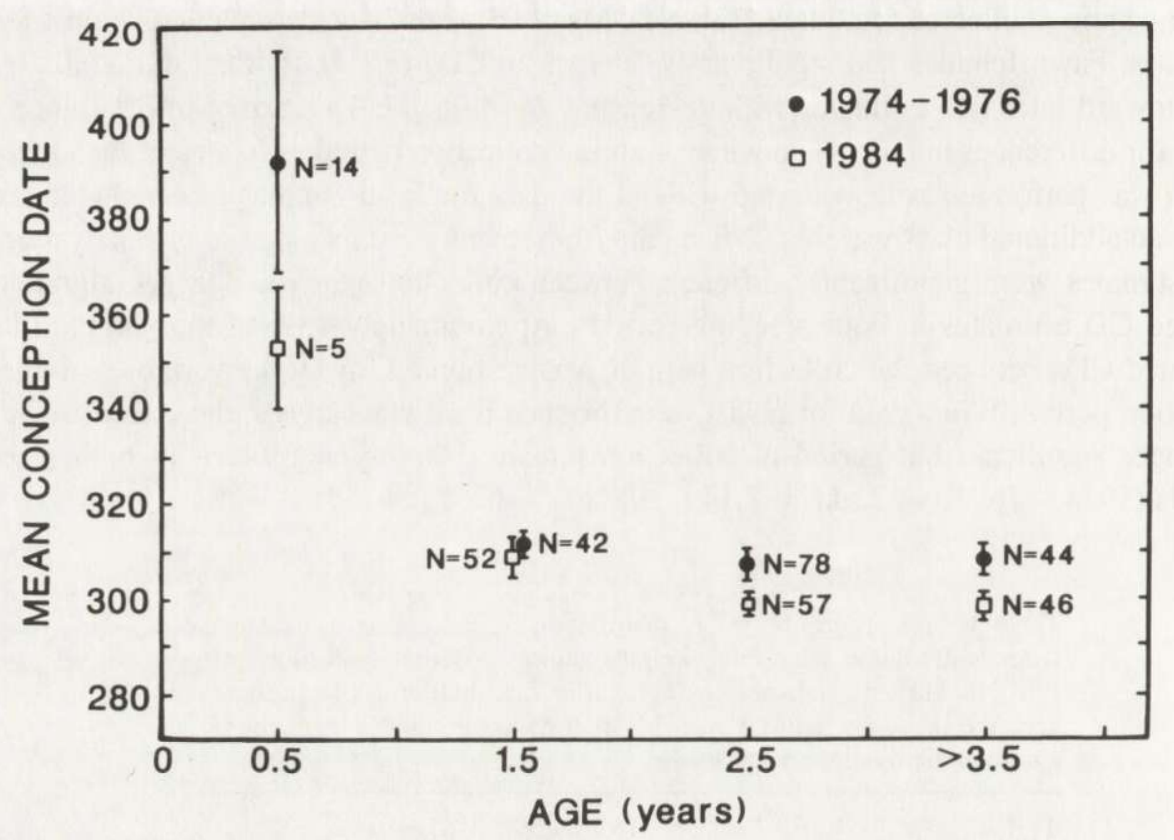

Fig. 1. Mean conception date $( \pm 1 \mathrm{SE})$ of female white-tailed deer of different age classes $(0.5,1.5,2.5, \geq 3.5)$ on the Savannah River Plant. Estimates for the two time periods were made from size and other characteristics of fetuses collected in the late fall, winter and spring. Conception dates are expressed in Julian days with 1 January of the year following the main part of the breeding season of older females as day 366 .

in the age classes $\geq 2.5$ years old in the $1974-76$ sample bred significantly earlier than they did in 1984. However, when the proportional representation of females, by age class, in the samples was adjusted by their frequency of occurrence in the population, the mean CDs were not different $(1974-76, \bar{x}=317 \pm 2.9 ; 1984, \bar{x}=314 \pm 1.8)$.

$\mathrm{CD}$ varied significantly as a function of fetal number without but not with the effects of female age removed. Fawns breed later (Fig. 1) than adults and generally have 1 fetus (Rhodes et al. 1985). The best estimate of CD was from the late winter - spring collected fetal data for the two annual periods $(1975-77,1985)$. Means and variance for these periods were not significantly different, and the values were pooled to calculate an overall frequency distribution of conception dates (Fig. 2) for the 101 pregnant females in the combined sample. Mean CD was 20 November \pm 27 days for adults and fawns combined and 13 November \pm 15 days for adults only. The frequency distribution of conception dates (Fig. 2) was not normal but was leptokurtotic and skewed toward later dates when all data were considered, and primarily leptokurtotic when data for only adult females were considered. The expected coefficients of skewness and kurtosis for a normal distribution are both zero. The coefficients of skewness and kurtosis for the overall distribution of conception dates were 2.06 and 6.25 , respectively. 


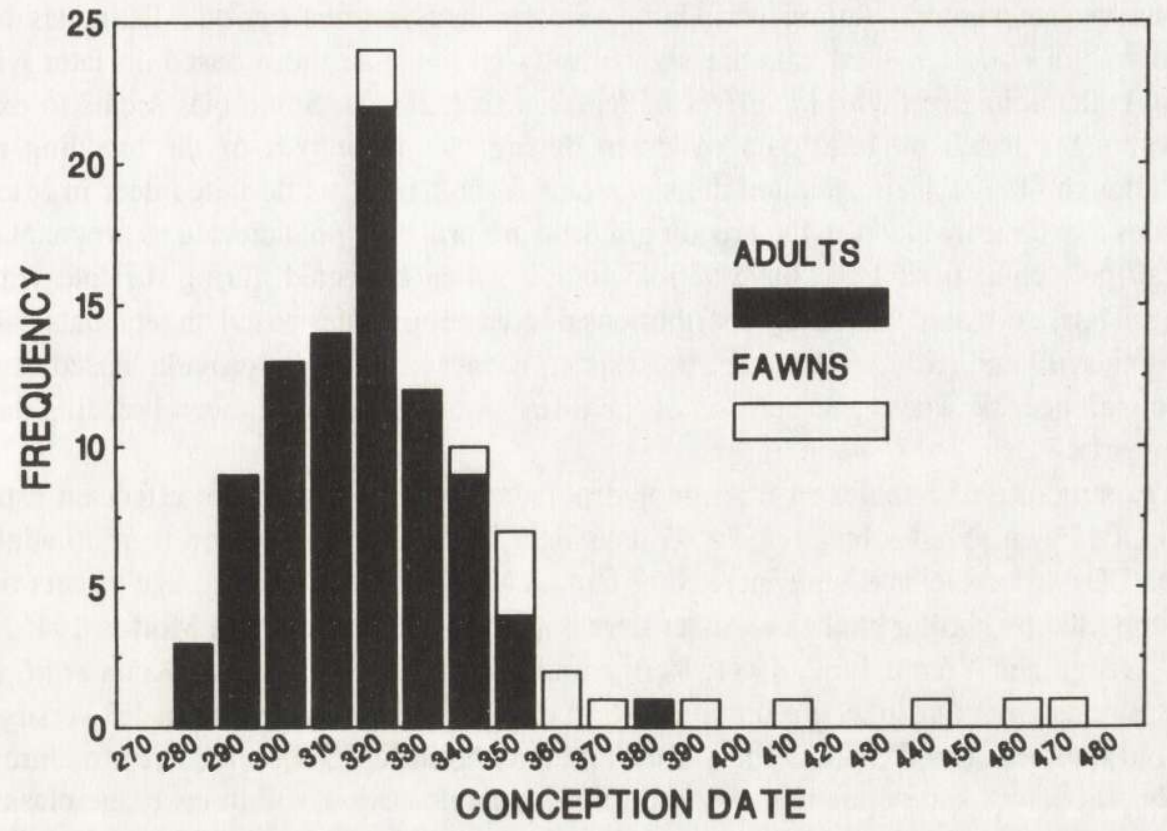

Fig. 2. Frequency distribution of conception dates for white-tailed deer females from all age classes on the Savannah River Plant estimated from late winter-spring fetal size and other characteristics collected during the $1974-76$ and 1984 breeding seasons. Conception dates are expressed in Julian days with 1 January of the year following the main part of the breeding season of older females as day 366. Numbers on the horizontal axis represent the median value of each histobar (e.g. the bar labeled 330 contains animals with conception dates from 326 to 335 ).

\section{Discussion}

The time of year that reproductive data are collected influences the frequency distribution of conception dates (Table 1). Our best estimate of the frequency distribution shows a highly leptokurtic distribution skewed toward later CDs (Fig. 2). Inclusion of the data for the fawns in the distribution causes the positive skewness. CDs for older females tend to be highly clumped within a short time period as indicated by their leptokurtic distribution. Distributions that include fetal data taken later during the year tend to be skewed towards later CDs and more leptokurtic than those distributions that include only fetal data from early breeding females. A highly leptokurtic distribution of CDs might be expected if constraints on the timing of breeding greatly reduces the success of breeding outside some narrow time period. Skewed distributions could result from the relaxation of the constraints for one end of the distribution. Fawns in this South Carolina herd attempt to successfully breed probably because of the mild winter climate characteristic of the region. The distribution of CDs might be expected to become platykurtotic (a negative coefficient of kurtosis) in even milder subtropical climates. 
The significant difference between the estimated CDs based on fetal data collected in the fall versus late winter - spring periods is reflected in both time periods. Estimates of CDs based on fall collected fetal data are significantly earlier than those based on later winter spring collections even with the effect of female age removed. Some bias seems to exist for our estimates based on fetal data collected during the major part of the breeding period. McCullough (1979) acknowledged the same bias for a herd of white-tailed deer in Michigan. Females that conceive later in the breeding season are probably not detected as pregnant during the fall collection period but have visible fetuses when collected during the late winter or spring. Thus, estimated frequency distributions of conception dates based on fetal data collected during the fall and early winter must be suspect, because these data provide biased estimates of the variance, skewness and kurtosis of the distribution as well as a mean breeding date that is too early.

Age structure of females in the sampled population has a significant effect on estimated mean CD. Fawn females breed about 45 days later in the breeding season than do adults and earlier CDs are associated with increasing female age (Fig. 1). Observed age effects on CDs are supported by similar studies on other deer populations (Cheatum and Morton 1946, Nixon 1971, Ozoga and Verme 1982, 1984; Verme and Ullrey 1984). However, Knox et al. (1988) found a nonsignificant $(p>0.20)$ trend toward earlier first estrous cycles in 1.5 versus $\geq 2.5$ year old females. The mean $\mathrm{CD}$ for a deer herd may be influenced by the age structure of the female fraction of the population. If proportional representation within each age class in the sample differs from that within the population then the CD estimate will be biased. Females of all ages were harvested during hunts, and the various age classes were well represented in our overall sample (Dapson et al. 1979).

Estimated mean CDs generated from late winter - spring collected fetal data in the breeding seasons of $1974-76$ and 1984 were not significantly different when compared both with and without adjustments for female age. Fall genrated estimates of mean CDs for these two breeding periods were significantly different, and the absolute difference between mean CD estimates by collection period are greater for the 1974 - 76 than for the 1984 period. Distributions of pregnant females in the various age classes in the samples from the falls of $1974-76$ and 1984 were not significantly different. Thus, a bias related to differential representation of the female age classes in the two fall samples cannot be used to explain the earlier CDs found in the $1974-76$ breeding period. A more likely explanation for the observed difference in CDs of females in the two fall periods is the significantly earlier CDs for females $\geq 2.5$ years old sampled in the $1974-76$ period vs those for females of the same ages collected in 1984 .

Earlier CDs of older females in the 1974 - 76 breeding period may be linked to the percentage of fawn breeding which occurred in each cohort. If higher levels of fawn breeding occurred in the years when the older females in our samples were fawns, then in subsequent years these females may breed later. The opposite is true in years of low fawn breeding. The incidence of fawn breeding has been relatively high (40\%) over the years in the Savannah River Site herd, and lower levels of fawn breeding were observed in the years preceding the 1974 - 76 sampling period than in those preceding the 1984 period (Rhodes et al. 1986). Females that conceive earlier in the breeding season have higher prebreeding levels of body fat than females that breed late (Cothran et al. 1987). Prolonged lactation probably delays 
replenishment of body fat stores and subsequent CDs (Cotharn et al. 1987). These data support the hypothesis that females that first breed late in the season as fawns and have nursing offspring during the following breeding season may breed late throughout their lives, and does in herds with characteristically high percentages of fawn breeding may breed later than those with low or no fawn breeding in the same environment. Future research will be needed to clarify and test this important hypothesis. It is still possible that CDs could vary between years when deer have markedly different body conditions as they are known to have on the Savannah River Plant (Johns et al. 1984).

Changes in environmental factors such as photoperiod or resource availability are also thought to cause temporal shifts in the timing of reproduction of female white-tailed deer (McDowell 1970, McGuinnes and Downing 1977). Demographic chracteristics such as density or sex ratio are also thought to influence the timing of conception (Jacobson et al. 1980). However, none of these factors are likely to be responsible for the temporal shift in CDs observed on the Savannah River Plant between the breeding periods of $1974-76$ and 1984 . Photoperiod effects were essentially the same in both time periods. Habitat effects on fetal number have been observed in the deer herd (Johns et al. 1977, Rhodes et al. 1985), but no significant differences were found between the estimated CDs of females among habitat types in either time period. The sex ratio of deer in the Savannah River Plant herd, estimated from hunt collected data, has remained essentially 1:1 since 1974 (Dapson et al. 1979), and deer densities in the herd have decreased slightly from 1974 to the present (Scribner et al. 1985). Rhodes et al. (1985) found no evidence for density dependent effects on fetal number in this deer herd. In addition, a change in CDs should have resulted in an earlier not a later CD if simple density dependent effects were involved. Since deer in this herd occur in small groups (Manlove et al. 1976) and have an even sex ratio, later CDs are probably not due to a scarcity of males (Jacobson et al. 1980).

Our best estimate of the mean CD ( \pm 1 SE) for females of all age classes on the Savannah River Plant, generated from spring collected fetal data $(1974-77,1985)$, is 20 November \pm 27 days and for adults only 13 November \pm 15 days. The unadjusted mean CD for all age classes was 22 November \pm 33 days (Fig. 2). This value is within the range of mean CDs reported for other herds (Illinois, November $22-28$, Roseberry and Klimstra 1970; Ohio, November 3 - 16, Nixon 1971; Florida, August 10, October 7, November 2, February 21, February 23, Richter and Labisky 1985). The mean CD for this herd is also consistent with conclusions about the parturition period based on evidence for lactation in females collected in the fall (Rhodes et al. 1986). Mean CD did not change significantly over years.

Most adult females (95\%) breed within a 2-month period, and some females could go through estrus up to three times during this period. The shape of the frequency distribution of CDs leads us to conclude that multiple estrus is not a frequent occurrence in this South Carolina herd, and other factors are probably responsible for the observed variance in CDs. Most red deer (Cervus elaphus Linnaeus, 1758) females are also successfully bred during their first estrus cycle (Clutton-Brock et al. 1982). A time series analysis of females with corpora lutea should allow a partial estimate of the occurrence of recycling through estrus. If the number of breeding males are limiting, then females should frequently recycle through estrus, and the distribution should be platykurtic and/or positively skewed because of late breeding adult 
females. Neither of these phenomena are observed and $65 \%$ of the adult females are bred within one month.

Regional variation in mean $\mathrm{CD}$ is observed among deer herds and may be attributed to a number of environmental and demographic characteristics (Richter and Labisky 1985). Variance, skewness, and kurtosis of distributions about mean conception dates have not been addressed in terms of regional variability or factors that affect distributional moments. To quantitatively assess variation in breeding activity among deer herds, estimates of the distributional moments of the data must be based on the data from a large number of females. However, estimates of skewness and kurtosis for CD distributions are rarely provided in the literature and may be biased by small sample sizes or variations in the age composition of the sampling units. The range and standard deviation of CDs are often given and may be suitable for comparisons across regions. Variation in CDs within the Savannah River Plant population is at least as great as that observed in other southeastern deer herds (Jacobson et al. 1980, Teer et al. 1965), midwestern herds (Nixon 1971, Roseberry and Klimstra 1970) and northern herds (Hesselton and Jackson 1974, Cheatum and Morton 1946, McCullough 1979), where 95\% of adult females are bred during $1-2$ months at all latitudes. Leptokurtotic distributions of CDs have also been observed in fallow deer in England (Armstrong et al. 1969) and red deer in Scotland (Clutton-Brock et al. 1988). In the absence of obvious habitat effects on length of breeding season, social factors may be acting to constrain the time of breeding of deer herds. Establishing the relative importance of social factors in constraining reproduction and the frequency distribution of reproduction over time in mammals should be a high priority of future research.

Acknowledgements: This research was supported by a contract (DE-AC09-76SROO819) between the University of Georgia's Institute of Ecology and the U. S. Department of Energy. Other groups cooperating in this research include: the personnel of E. I. DuPont de Nemours Company, the U. S. Forest Service at the Savannah River Plant and the Department of Aquaculture, Fisheries, and Wildlife at Clemenson University; the South Carolina Department of Wildlife and Marine Resources granted permission to conduct winter and spring collections. Thanks are extended to Drs. R. K. Chesser, E. G. Cothran, and colleagues at the Savannah River Ecology Laboratory for assistance in data collection. Drs. T. T. Fendley, J. R. Sweeney, and D. C. Guynn, Jr. commented on an early draft of the manuscript.

\section{References}

Armstrong R. A. 1950. Fetal development of northern white-tailed deer (Odocoileus virginianus borealis Miller). Am. Midland Nat. 43: $650-666$.

Armstrong N., Chaplin R. E., Chapman D. I. and Smith B. 1969. Observations on the reproduction of female wild and park Fallow deer (Dama dama) in southern England. J. Zool. (London) 158: 27 - 37.

Barr A. J., Goodnight J. H., Sall J. P. and Helwig J. T. 1985. SAS user's guide: Basics. SAS Institute, Inc. Raleigh, North Carolina: $1-1292$.

Chapman D. and Chapman N. 1975. Fallow deer. Lavenham Press Limited: 139 - 156

Cheatum E. L. and Morton G. H. 1946. Breeding season of white-tailed deer in New York. J. Wildl. Manage. 10: $249-263$.

Clutton-Brock T. H., Guinness F. E. and Albon S. D. 1982. Red deer. Behavior and ecology of two sexes. Univ. Chicago Press, Chicago: $1-378$.

Clutton-Brock T. H., Albon S. D. and Guiness F. E. 1988. Reproductive success in male and female red deer. [In: Reproductive success studies of individual variation in contrasting breeding systems. T. H. Clutton-Brock, ed.]. Univ. Chicago Press, Chicago: 325 - 343. 
Cothran E. G., Chesser R. K., Smith M. H. and Johns P. E. 1987. Fat levels in female white-tailed deer during the breeding season and pregnancy. J. Mammal. 68: $111-118$.

Dapson R. W., Ramsey P. R., Smith M. H. and Urbston D. F. 1979. Demographic differences in contiguous populations of white-tailed deer. J. Wildl. Manage. 43: 889-898.

Fisher R. A. 1958. The genetical theory of natural selection. Dover Pub. Inc., London: $1-284$.

Hamilton R. J., Ivey T. L. and Tobin M. L. 1985. Aging fetal white-tailed deer. Proc. 39th Ann. Conf. Southeast. Assoc. Fish and Wildl. Agencies 39: $374-379$.

Hesselton W. T. and Jackson L. 1974. Reproductive rates of deer in New York State. J. Mammal. 21: 135 - 152.

Hudson P. and Browman L. G. 1959. Embryonic and fetal development of the mule deer. J. Wildl. Manage. 23: $295-304$.

Jacobson H. A., Guynn D. C., Griffin R. N. and Lewis D. 1980. Fecundity of white-tailed deer in Mississipi and periodicity of corpora lutea and lactation. Proc. Southeastern Assoc. Fish and Wildl. Agencies 33: 30 - 35 .

Johns P. E., Baccus R., Manlove M. H., Pinder J. E., III and Smith M. H. 1977. Reproductive patterns, productivity and genetic variability in adjacent white-tailed deer during the breeding season. Proc. Southeastern Assoc. Fish and Wildl. Agencies 31: 167-172.

Johns P. E., Smith M. H. and Chesser R. K. 1984. Sex and age effects of seasonal fat levels in a southeastern white-tailed deer herd. J. Wildl. Manage. 48: 969 - 972.

Knox W. M., Miller K. V. and Marchinton R. L. 1988. Recurrent estrous cycles in white-tailed deer. J. Mammal. 69: $384-386$.

Manlove M. N., Smith M. H., Hillestad H. O., Fuller S. E., Johns P. E. and Straney D. O. 1976. Genetic subdivision in a herd of white-tailed deer as demonstrated by spatial shifts in gene frequencies. Proc. Southeastern Assoc. Fish and Wildl. Agencies 30: 487 - 492.

McCullough D. R. 1979. The George Reserve deer herd. Univ. Michigan Press: 1 - 271.

McDowell R. D. 1970. Photoperiodism among breeding eastern white-tailed deer (Odocoileusvirginianus). Trans. Northeast Section, Wildl. Society: $19-38$.

McGuinnes B. S. and Downing R. L. 1977. Factors affecting the peak of deer fawning in Virginia. J. Wildl. Manage. 41: 715 - 719 .

Morrison J. A., Trainer C. E. and Wright P. L. 1959. Breeding season in elk as determined from known-age embryos. J. Wildl. Manage. 23: $27-34$.

Nixon C. M. 1971. Productivity of white-tailed deer in Ohio. Ohio J. Sci. 71: $217-225$.

Ozoga J. J. and Verme L. J. 1982. Physical and reproductive characteristics of a supplementally-fed white-tailed deer herd. J. Wildl. Manage. 46: $282-301$.

Ozoga J. J. and Verme L. J. 1984. Effect of family-bond deprivation on reproductive performance in female white-tailed deer. J. Wildl. Manage. 48: 1326 - 1334.

Rhodes O. E., Jr., Scribner K. T., Smith M. H. and Johns P. E. 1985. Factors affecting the number of fetuses in a white-tailed deer herd. Proc. Southeastern Assoc. Fish and Wildl. Agencies 39:380 - 388 .

Rhodes O. E., Jr., Novak J. M., Smith M. H. and Johns P. E. 1986. Assessment of fawn breeding in a South Carolina deer herd. Proc. Southeastern Assoc. Fish and Wildl. Agencies 40: 430 - 437.

Richter A. R. and Labisky R. F. 1985. Reproductive dynamics among disjunct white-tailed deer herds in Florida. J. Wildl. Manage. 49: 964 - 971.

Roseberry J. L. and Klimstra W. D. 1970. Productivity of white-tailed deer on Crab Orchard National Wildlife Refuge. J. Wildl. Manage. 34: $23-28$.

Scribner K. T., Wooten M. C., Smith M. H. and Johns P. E. 1985. Demographic and genetic characteristics of white-tailed deer populations subjected to still and dog hunting. [In: Proc. of a Symposium on Game Harvest Management. S. L. Beasom and S. F. Roberson, eds]. Caesar Kleberg Wildlife Research Inst., Kingsville: $197-212$.

Severinghaus C. W. 1949. Tooth development and wear as criteria of age in white-tailed deer. J. Wildl. Manage. 13: $195-216$.

Short C. 1970. Morphological development and aging of mule and white-tailed deer fetuses. J. Wildl. Manage. $34: 383-388$. 
Teer J. G., Thomas J. W. and Walker E. A. 1965. Ecology and management of white-tailed deer in the Llano Basin of Texas. Wildl. Monogr. 15: 1 - 62 .

Verme L. J. 1965. Reproductive studies on penned white-tailed deer. J. Wildl. Manage. 29: 74 - 79.

Verme L. J. and Ullrey D. E. 1984. Physiology and nutrition. [In: White-tailed deer. L. K. Halls, ed.]. Stackpole Books, Harrisburg: $91-118$.

Received 6 March 1989, revised 25 February 1991, accepted 5 March 1991. 